Papers in Evolutionary Economic Geography

$$
\text { \# } 17.22
$$

R\&D Policy and Technological Trajectories of Regions: Evidence from the EU Framework Programmes

Wolf-Hendrik Uhlbach, Pierre-Alexandre Balland and Thomas Scherngell 


\title{
R\&D Policy and Technological Trajectories of Regions: Evidence from the EU Framework Programmes
}

\author{
Wolf-Hendrik Uhlbach ${ }^{1}$, Pierre-Alexandre Balland ${ }^{1}$, and Thomas Scherngell ${ }^{2}$ \\ ${ }^{1}$ Utrecht University, Heidelberglaan 2, 3584 CS Utrecht, The Netherlands \\ ${ }^{2}$ AIT Austrian Institute of Technology GmbH, Donau-City-Straße 1, 1220 Vienna, \\ Austria
}

August 28, 2017

\begin{abstract}
It is widely acknowledged that new technological specializations of regions are to a large extent driven by the recombination of existing knowledge and capabilities. Since this process is path-dependant and self-reinforcing, it can easily lead to technological lock-ins. A key issue is therefore to evaluate whether public policy can impact technological trajectories of regions and how it can be more effective. To address this issue, we analyze quantitatively and systematically the relation between R\&D subsidies and new technological specializations of European regions from 1999 to 2010. R\&D subsidies are identified by using the EU Framework Programmes (FP) from the EUPRO database, and matched with patent documents from the OECD-REGPAT database. Using a fixed-effects linear probability model, our results indicate that FP participations have a positive but relatively small effect on the development of new specializations of regions, and that it can compensate for a lack of local related capabilities. We also find evidence that R\&D subsidies have the highest impact if the level of relatedness with the new technology is neither too low (policy can not build a cathedral in the desert) nor too high (if all the capabilities are already present there is no need for policy).
\end{abstract}

Key Words: Regional Diversification, Technological Change, R\&D subsidies, EU Framework Programmes

JEL: O31, O33, O38, O52 


\section{Introduction}

Innovation and technological change have been identified as key for regional and economic development policies, as the ability to renew and adapt their technological and industrial structure is crucial for regions to keep growing in the long-run (e.g. Nelson \& Winter, 1982; Boschma \& Gianelle, 2014; Balland et al., 2017). Therefore, it has long been an effort of science, technology and innovation (STI) policies to promote inventive activities in regions with the goal of upgrading and changing their technological and industrial base. This was also a special concern of the European cohesion policy. However, many efforts did not succeed and resulted in an inefficient use of the public budget (Barca, 2009). A possible reason for such failures is that these efforts did not sufficiently take into account the technological make up of a region (Foray et al., 2009). Recent research underlines the importance of such structural factors and generates a growing body of evidence, suggesting that countries and regions tend to diversify by developing new specializations in activities that are closely related to their current ones (Hidalgo et al., 2007; Rigby, 2015; Boschma et al., 2015; Petralia et al., 2017; Gao et al., 2017).

This literature is based on the idea that technological diversification is a process of knowledge transfer (Boschma et al., 2013) from one technology to another. But the ease of this process differs by the extent to which pairs of technologies build on similar knowledge and capabilities. If two technologies are very similar in such terms, they can be considered as related (Balland et al., 2017; Hidalgo et al., 2007). Thus, when developing new activities, firms and organisations tend to exploit technological opportunities that are closely related to their current activities, which is known in the literature as the principle of relatedness (Hidalgo et al., 2017). This is more feasible, as most of the necessary knowledge and skills are already available (Cohen \& Levinthal, 1990), as well as less risky, as inventors are more familiar with components they combine (Fleming, 2001). Such firm level behaviour (Neffke et al., 2011; Balland, 2016) can consequently also be observed as a branching processes on the regional level (Boschma et al., 2012). Empirical studies prove the validity and predictive power of relatedness as a determinant of technological change in different geographical contexts and scales. Using export data on the country level, Hidalgo et al. (2007) find that countries tend to diversify into products closely related their existing portfolio. Boschma et al. (2013) show in a study on Spanish regions that the effect is even stronger on the regional level. As knowledge dynamics are more directly captured by looking at technologies, a row of studies (see e.g. Rigby, 2015; Essletzbichler, 2015; Boschma et al., 2015; Kogler et al., 2017; Balland et al., 2017; Colombelli et al., 2014), confirmed and extended these results using patent data on the regional level.

Despite the large evidence showing the importance of relatedness as an enabler of diversification, too few studies acknowledge factors beyond the idiosyncratic technological make up of regions. A few notable exceptions are Cortinovis et al. (2016) and Boschma and Capone (2015) who find that institutions, as well as liberal market economies - as compared to coordinates market economies - seem to facilitate diversification into less related activities. Besides institutions, Petralia et al. (2017) also highlighted the importance of the level of economic development while Gao et al. (2017) shows the importance of geographical proximity and inter-regional learning. However, besides such structural factors, one can also think of much more direct channels through which diversification processes can be steered. Thus, by subsidizing research and development (R\&D) activities and by prioritizing certain fields, policy makers might have the potential to influence the intensity as well as the direction of diversification processes (Aghion et al., 2012). 
Historically, there are many examples in which major breakthrough inventions, especially in the field of ICT (e.g. Blumenthal, 1998; Arnold, 2012), biotechnology (Lazonick \& ner Tulum, 2011) and nanotechnology (Motoyama et al., 2011), sprung from government incentives. Gaining a better understanding of the effectiveness of funding in the development of new specialisations under consideration of region specific technological structures, is therefore of utmost importance for an effective design of policy tools. More recently, these considerations are also taken up to design policies, as for instance in the context of the smart specialisation strategy (Balland et al., 2017).

The aim of this paper is therefore to shed more light on the effects of collaborative R\&D subsidies, represented by the EU Framework Programmes, on the emergence of new technological specialisations in European regions. It will more specifically ask how far subsidization of a certain technology will lead a region to develop a comparative advantage in the respective technology. Secondly, it will investigate to what extent subsidization can allow regions to diversify into less related technologies.

In so doing, we contribute to the literature in two ways. Our first and methodological contribution is the employment of a text classification approach in order to link the textual descriptions of R\&D projects to technologies in which patents are likely to result. Patents are a common measure for innovation, as they entail rich information about the technology and locus of invention. Despite inherent shortcomings, such as differing patenting strategies between organisations and industries and the omission of the service sector, this measure is the best available (Acs et al., 2002). Secondly, we extend the understanding of regional branching processes by investigating potential effects of public R\&D subsidisations. Our analyses suggest a positive association between regions' participations in technology-specific collaborative R\&D projects and the probability for the respective technology to enter a region's portfolio. Further, by taking into account the region's technological structure, we find that such participations can also, up to a certain extent, compensate for a lack of related knowledge and capabilities. We also find evidence that R\&D subsidies have the highest impact if the level of relatedness with the new technology is neither too low nor too high.

The remainder of the paper is structured as follows. After building the theoretical framework (section 2), the empirical set-up will be explained in section 3. Section 4 will be dedicated to the results, followed by a discussion and conclusion (section 5).

\section{Theoretical Framework}

Traditionally, innovation policies aim at fixing market and system failures (Aghion et al., 2009). This is done by subsidizing a firm's R\&D activity in order to make up for the involved risk and potential knowledge spillover to competing firms (Arrow, 1962) and also by promoting collaborative research projects in order to facilitate knowledge spillovers between firms (Broekel, 2015). Government can affect both chance for product development and market success, impacting indirectly firm's innovative effort (Lee \& Lim, 2001). The main goal of such interventions, however, is to foster inventive activities and not to promote technological diversification. When it comes to the latter, a number of additional problems arise that policy needs to address. Weber and Rohracher (2012) refer to these as transformational system failures. These refer to the fact that regional transformations, as the result of technological change, are a collective process in which different actors on the regional level need to align their priorities and efforts (Crespo et 
al., 2013; Vicente, 2016). But the question remains whether R\&D programmes that were not originally designed to foster diversification, could also have done that anyway.

There are theoretical considerations that different types of subsidisations can lead to different outcomes with respect to technological change in regions (Frenken, 2017). The ways through which such subsidization can shape technological change in regions are plentiful. They are, to a lesser extent, inputs in a linear innovation process, but they can more likely contribute to complex mechanisms of market formation, incentive setting, risk compensation and the exchange of knowledge (e.g. Aghion et al., 2009; Mazzucato, 2016). In what follows, we will therefore first assess the potential channels through which these subsidies can foster any new technological specialisations in regions, and second assess those, through which they can specifically compensate for a lack of available knowledge and capabilities.

The first channel are financial resources. These relate very much to traditional approaches of STI policies, which tried to compensate for the risk of research (Fleming, 2001). Further, financial resources are also a key resource to foster diversification activities as they can be used in a very flexible way (Chatterjee \& Wernerfelt, 1991). However, as this is a novel approach of evaluating STI policies, there are, with the notable exception of Broekel (forthcoming), no preceding studies looking at technology-specific effects of R\&D subsidisations at the regional level that also take into account the technological make-up of regions, to review. However, there are plenty of studies looking at just the technological effects or just the firm and regional level.

A row of studies has investigated the relationship between public funding of research and the innovative productivity and finds a positive effect in the amount of R\&D subsidization and inventive outputs (e.g. Guellec \& De La Potterie, 2000). Another set of studies looked at the relationship between STI policies and the development of new technologies. Nemet (2009) in a study on wind power patenting, finds that funding tools, directed towards exploration, can foster inventive activities in the technology fields they are directed to. In another study by Peters et al. (2012), it is shown that domestic R\&D funding for photovoltaic research is associated with a higher patenting activity in the respective technology. Also, Frenken (2017) argues that generic subsidizations will lead organisations to exploit knowledge domains in proximity to their existing competencies. Based on this, our first hypothesis $\left(H_{1}\right)$ will be as follows:

\section{$H_{1}$ : Regions are more likely to specialise in technologies for which they receive} RED subsidies.

Despite the wide acknowledgement of the positive effects of related variety and relatedness on a region's short term development (e.g. Frenken et al., 2007), little evidence is available about its effects in the long-term (Boschma, 2015). Theoretical considerations however suggest that diversification strategies solely focusing on relatedness, as well as too much relatedness within a region, can be connected to negative outcomes. Thus, bounded rational behaviour and rent seeking will lead to the exploitation of few knowledge domains (Arthur, 1994). As a consequence, a region's specialisation will deepen and diversification will predominately take place into related domains (Kogler et al., 2017). This will increase the region's vulnerability to external shocks (McCann \& Ortega-Argilés, 2011) and may result in the region's lock-in in the long-term (Boschma, 2015). Therefore, it is commonly argued for a need for unrelated diversification from time to time (e.g. Boschma, 2017; Frenken, 2017). This, however, is connected to a range of constraints. In this context, certain policies, such as STI policies, when designed in an appropriate way, can help to 
overcome these (Foray et al., 2009). These ideas are depicted by Figure 1, in which technology 6 is most related to the region's portfolio, but technology 8 gets subsidized. The question will therefore be to what extent research efforts are directed towards field 8 and how this will change the entry probabilities of the respective technologies.

The failure of past STI policies, aimed at the promotion of high-technology ventures in regions, irrespective of pre-existing knowledge and capabilities, underline the importance of the underlying technological structure when designing such policies on the regional level (Boschma \& Gianelle, 2014). Collaborative R\&D programmes, however, actively foster knowledge spillover between collaborating organisations. Thus, lacking capabilities of one organisation can be complemented by the strengths of another one. This was prominently pointed out by Bathelt et al. (2004) who argue that it is necessary for regions to have close collaborations to other distant regions in order to profit from different sets of skills and information (Breschi \& Lenzi, 2013). Evidence for such spillovers are reported by Czarnitzki and Fier (2003) - who find evidence for knowledge flows between firms participating in publicly funded R\&D consortia - and Wanzenböck et al. (2014) - who find positive effects of a region's embeddedness in R\&D collaboration networks on their inventive output. Additionally, this is supported by Hazır et al. (2016) who look at the patenting activities caused by collaborations of the Framework Programmes (FP) in the ICT sector. By also looking at the characteristics of collaborators, Broekel et al. (2015) find that such collaborations are more effective when giving access to different but related knowledge. However, the establishment of such meaningful pipelines can be costly (Bathelt et al., 2004), which may increase additional effects of policy interventions. Thus, by setting rules for the composition of consortia, policy makers can regulate the degree of potential spillovers.

\section{Figure 1: Illustration of Research Questions}

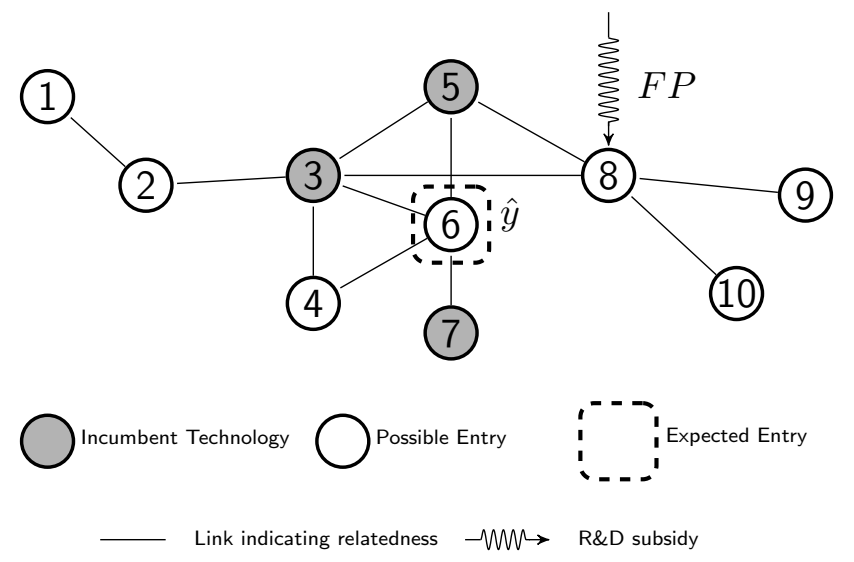

Notes: The figure depicts the technology space of a region in which each node represents a technology and the edges indicate whether two technologies are related to each other. In this example the region has a revealed technological advantage (RTA) in technologies 3,5 and 7. The standard model would predict the entry of technology 6 as it is the most related to the regional portfolio (relatedness density (RD) $=75$ ). Technology 8 however is less related $(R D=50)$ but the regions $R \& D$ activities in this field are supported by public funding.

Further, when theorizing about the effect of subsidization, it is also important to note that the distribution of subsidisation is not random but based on certain principles. Either they will be allocated in a competitive way (Pavitt, 1998) or based on strategic considerations to deliberately foster the emergence of new technologies (Acemoglu et al., 
2012). When the former applies, R\&D subsidization can be argued to reinforce existing specializations and technologies in their close proximity, as a high level of competitiveness detriments the building up of new capabilities (Pavitt, 1998). When the latter applies, the additionality of subsidization can be expected to bigger (Frenken, 2017). Similar arguments were put forward by the new industrial policy literature (Rodrik, 2004; Aghion, Boulanger, \& Cohen, 2011; Foray et al., 2009). Its core arguments are that public policy plays a crucial role in starting diversification processes which otherwise would not occur easily (Rodrik, 2004). More recent work by e.g. Mazzucato (2016) links industrial and innovation policy. In this, it is argued that public policy can not only de-risk but also directly create technological opportunities and markets. It is also argued that many funding schemes, especially in the European context, are inherently directed towards certain sectors in their implementation (Azar \& Sandén, 2011). Considering these potential channels, our second hypothesis will therefore be as follows:

$H_{2}$ : Funding tends to compensate for a lack of related capabilities, i.e. there is a negative interaction effect between relatedness and RED subsidies.

\section{Data and Methods}

In this section, we will describe the empirical setting and our approach to estimate the effects of public R\&D subsidisation on technological change in European regions. As innovation policies are designed in different ways between countries, we focus our analysis on only one funding tool, which are the EU Framework Programmes. These were established in 1984 in order to strengthen the technological capabilities in the European Union (Scherngell \& Lata, 2013). From the beginning, one of their main characteristics were the fostering of collaborative $R \& D$ projects. While early programmes mainly focused on the promotion of basic research, policy changed with the fifth Framework Programme towards more societal orientation and the translation of scientific advances to market relevant applications (Arnold, 2012). Therefore, we will only consider projects from FP5 onwards.

The data on FP participations was extracted from the EUPRO data base, which contains information about funded projects and their participants on the NUTS2 level and covers all FPs, i.e. 1984-2013. Yet, the information on the latest available programme, FP7, is not completely in the data base yet, and reliable information is available until 2012 (Heller-Schuh et al., 2015). The study area covers collaborative research projects from FP5 to FP7. Since not all sub-programme areas from the FPs are relevant for technological diversification, only projects from the cooperation programme from FP7 (excluding Socioeconomic Sciences and Humanities) were selected. Relevant sub-programmes from FP5 and FP6 were selected based on the concordance table provided by Rietschel (2010). This resulted in a total of 15,983 projects covering the years 1999-2011. In order to map the technological change in European regions we make use of the OECD-REGPAT data set. To capture the actual locus of knowledge production in a more detailed manner, patent applications, fractionalized by their inventors' home addresses, were used. More detail regarding this data source and the regionalisation of patent applications is provided by Balland et al. (2017). Lastly, the remaining control variables on the regional and technological level were retrieved from EUROSTAT. 


\subsection{FP-Technology Matching}

The big challenge for the empirical analysis in this study is to combine two data sets that draw on fundamentally different classification logics; in essence, FP projects have to be assigned to technology domains appearing in patents. This is not feasible based on the existing classifications in the two datasets. Information of projects recorded in EUPRO, however, offer textual descriptions such as project titles, project abstracts, objectives and achievements as well as a list of resulting documents and their titles. Since the amount and quality of the textual information available is not sufficient to delineate 613 IPC classes in a reliable manner, the classification scheme used instead is the scheme of technology fields (TF), as proposed by Schmoch (2008). This summarizes the IPC classes to 35 distinct and balanced technology fields which can also be assumed to be more distinguishable based on their semantic descriptions ${ }^{1}$. While previous studies are limited to specific subprogrammes like ICT (e.g. Hazir et al., 2016) and assigns all projects belonging to the same sub-programmes to the same technologies, this article adds more nuance by taking into account the heterogeneity of the sub-programmes and conducting a matching on the level of individual projects ${ }^{2}$.

In order to link the FP projects to the technology fields, a machine learning technique, namely a maximum entropy classifier ${ }^{3}$, is applied. In order to be able to make predictions, this technique requires a large number of project descriptions that can be used as training documents. To achieve this, out of the 15,983 selected projects, a random sample is retrieved, and uniquely classifiable projects are assigned to one TF manually. To improve the assignment, Google Patent Search was used to look up the technological affiliation of certain terms. In so doing, 1,001 projects were assigned manually. After pre-processing the textual information, which entails removing stop words and non-alphanumerical symbols, as well as weighting terms, the classifier is fitted and applied to the remaining unclassified projects. As a result, a project-technology matrix is returned where the elements indicate the probability with which a project belongs to a certain TF. As FP projects are also generic and can address different technological fields, for each project a vector of up to five TFs with the highest probability is created and the corresponding probabilities is retrieved. Based on the assignment probability, projects are assigned fractionally with a certain weight to the TFs. In order to reduce the noise and wrong classifications, classifications with less than $5 \%$ probability are not assigned. On average, each project is assigned to $2.2 \mathrm{TFs}$. To evaluate the classification quality, two approaches were taken. First, the training dataset was split and 101 classified abstracts were reclassified. Second, an inventory of 295 patents resulting from $161 \mathrm{FP}$ projects from the FP7 ICT programme was used (Jacob et al., 2015). These tests reveal that between $51 \%$ (for ICT projects) and $63 \%$ (project abstracts) of the fields are predicted correctly. Overall, regarding the amount of available information and the number of classes, as well as the bias of the validation data towards ICT sector, these results will be considered as sufficient.

An important underlying assumption of the analysis is that funding for a certain technology is also allocated to regions that do not yet have a specialisation in the respective technology. Our data suggests that in $53.5 \%^{4}$ of all participations, this was the case.

\footnotetext{
${ }^{1}$ For the purpose of this study, fields 10 (Measurement) and 11 (Analysis of biological materials) as well as fields 14 (Organic fine chemistry) and 16 (Pharmaceuticals) were merged, resulting in 33 technology fields.

${ }^{2}$ This matching is available as part of the EUPRO database for research purposes.

${ }^{3}$ An implementation of this technique is provided by the 'maxent' package in R (Jurka, 2012)

${ }^{4}$ In this case, both revealed technological advantage (RTA) and number of participations were com-
} 
This may seem counter-intuitive, as participations in the FPs is highly competitive and is often argued to exploit existing strengths (e.g. Pavitt, 1998; Dekker \& Kleinknecht, 2008). However, the FPs are also a collaborative R\&D program in which consortia are made up of partners from different regions. It may therefore be the case that some of the project partners do not have a comparative strength in the technology field a project aims at but may as well be specialised in related technologies.

\subsection{Econometric Approach}

In order to estimate the respective effects of subsidization on the technological diversification of European regions, we employ a fixed effects panel regression approach. In so doing 282 NUTS2 regions (EU27, Switzerland, Norway and Iceland) for two four- year periods (2003-2006; 2007-2010) are used in which the independent variables were lagged by one period (1999-2002; 2003-2006). In this approach, however, relatedness and entry were computed on the level of 613 IPC classes, while funding related variables where computed on the level on 33 technology fields (Schmoch, 2008).

Table 1: Descriptive statistics

\begin{tabular}{lccccc}
\hline Statistic & $\mathrm{N}$ & Mean & St. Dev. & Min & Max \\
\hline entry & 284,508 & 0.11 & 0.31 & 0 & 1 \\
FP & 345,732 & 2.87 & 11.47 & 0.00 & 485.03 \\
RD & 345,732 & 17.79 & 12.94 & 0 & 100 \\
FP Dens & 345,732 & 29.84 & 20.88 & 0 & 94 \\
GDP/CAP & 300,983 & 21.15 & 10.64 & 1.43 & 62.98 \\
Pop. Dens & 337,763 & 338.36 & 820.46 & 2.05 & $9,216.67$ \\
GERD (1000) & 281,980 & 0.68 & 1.32 & 0.001 & 14.66 \\
Tech. Growth & 345,732 & 1.98 & 39.11 & -100.00 & 300.81 \\
\hline
\end{tabular}

Given our empirical setting, we employ - as in previous related works (see e.g. Boschma et al., 2015) - a fixed effects linear probability panel regression approach. This allows controlling for omitted variables on the regional and technology level that would otherwise be neglected. In order to adjust for correlation of errors within regions and technologies, the standard errors are clustered on the region and technology level. The model specification in scalar notation is as follows:

$$
\begin{aligned}
E N T R Y_{i, r, t}=\beta_{1} F P_{z, r, t-1}+\beta_{2} R D_{i, r, t-1}+\beta_{3} R E G_{r, t-1}+\beta_{4} T E C H_{i, t-1}+ \\
+\beta_{5} F P_{z, r, t-1} \times R D_{i, r, t-1}+\theta_{i}+\sigma_{r}+\alpha_{t}+\varepsilon_{i, r, t}
\end{aligned}
$$

In this model, the dependent variable $E N T R Y$ is a binary variable taking the value 1 if a region $r$ gains a specialisation (RTA) in a certain technology $i$, at time $t$, that it was not specialised in at period $t-1$; it takes the value 0 otherwise. $F P$ is a proxy for subsidisation intensity:

$$
F P_{z, r, t}=\sum_{p \in z} \frac{x_{p, r} * w_{p, z}}{k_{p, t}}
$$

puted on the level of 33 technology fields. In the final model, the RTA is computed on the level of 613 IPC classes while the participations remain at the level of technology fields. This set up leads to $71.3 \%$ of participations taking place despite of a lacking RTA 
As the absolute amount of project subsidisation might be skewed by technology-specific development costs, the size of consortia as well as the distribution of funds within them, we use, in line with Broekel (2015), the number of regional project participations as a proxy for public subsidizations. The variable $F P$ is consequently measured by the number of participations $x$ of a region $r$ in a project $p$, belonging to technology field $z$, weighted by the field weight $w$ and divided by the number of periods it covers $k$. Consequently, each technology $i$ belonging to a technology field $z$ receives the same amount of funding. The variable $R D$ denotes the relatedness density around a certain technology. This measure is widely used and describes how close a technology is to the existing technological portfolio of a region. In order to compute it, it is first necessary to construct a so-called technology or knowledge space (see Hidalgo et al., 2007). This network representation indicates which technologies are related to each other. For its calculation, the method of Rigby (2015) is applied. In this methodology, two technology classes are thought to be related when they are assigned to the same patents above a certain threshold. Thus, in a first step for each period, a co-occurrence matrix between technologies $i$ and $j(i, j=1, \ldots, m)$ is constructed. This results in a $m \times m$ matrix with the dimensions $613 \times 613$ IPC classes, with the diagonal set to zero. To further get the degree of relatedness between each pair of technologies, this matrix normalized using the association measure by Eck and Waltman (2009) adapted by Steijn (2017). In a final step, the matrix is dichotomized, such that value 1 indicates that two technologies are related, whereas value 0 indicates no such relatedness. This results in a complex network, in which some technologies are related to many others, while others are only related to a few (Frenken, 2017). Based on this, the relatedness density ${ }^{5}$ is computed as follows, where $\sigma$ indicates whether technologies $i$ and $j$ are related to each other:

$$
R D_{i, r, t}=\frac{\sum_{j \in r, j \neq i} \sigma_{i, j}}{\sum_{j \neq i} \sigma_{i, j}} \times 100
$$

The values of this variable range between 0 and 100, where a value of 0 indicates that no related technologies are existing in a region and a value of 100 indicates that all related technologies around technology $i$, are incumbent in region $r$. Next to $F P$ and $R D$, an interaction effect $F P \times R D$ between the participations and relatedness is included to test the second hypothesis. This will inform about the conditional importance of relatedness at different levels of subsidisation and vice versa. In a final step, observations that already have an RTA in period $t-1$ were deleted from the panel. Descriptive statistics are presented in Table 1.

Additionally, a set of control variables on the regional and the technology level are added. Thus, in order to test whether the entry of a certain technology is also influenced by the funding of related technologies, we construct a new variable, funding density (FP Dens). This variable is calculated analogously to the relatedness density and thus indicates the share of funded related technologies around a certain technology $i$. Formally it is expressed as follows, where $\gamma$ indicates whether technology $j$ gets funded or not:

$$
F P \text { Dens }_{i, r, t}=\frac{\sum_{j \in r, j \neq i} \gamma_{i, j}}{\sum_{j \neq i} \gamma_{i, j}} \times 100
$$

\footnotetext{
${ }^{5}$ The R package EconGeo (Balland, 2017) offers an easy implementation for the computation of these variables
} 
Table 2: Correlation Matrix

\begin{tabular}{lrrrrrrr}
\hline & entry & $\log (\mathrm{FP})$ & $\mathrm{RD}$ & FP Dens & GDP/CAP & Pop Dens & GERD \\
\hline entry & 1.000 & & & & & & \\
$\log (\mathrm{FP})$ & 0.068 & 1.000 & & & & & \\
RD & 0.140 & 0.257 & 1.000 & & & & \\
FP Dens & 0.123 & 0.544 & 0.516 & 1.000 & & & \\
GDP/CAP & 0.105 & 0.289 & 0.568 & 0.540 & 1.000 & & \\
Pop Dens & 0.032 & 0.170 & 0.133 & 0.263 & 0.303 & 1.000 & \\
GERD & 0.063 & 0.366 & 0.349 & 0.561 & 0.476 & 0.215 & 1.000 \\
Tech Grth & 0.017 & 0.017 & -0.003 & 0.010 & 0.005 & 0.0001 & 0.002 \\
\hline
\end{tabular}

Further to test for technological trends, we add the growth rate of a certain technology $i$ between period $t-1$ and $t$. We expect this variable to have a positive effect on the entry of technologies.

However, the branching process of a region also depends on its idiosyncratic properties. First, in order to control for the wealth of a region, the gross domestic product (GDP) per capita, is added. Further we add the population density and the gross expenditures for research and development (GERD) for each region and expect both to increase the probability for a technology to enter a region's portfolio. Descriptive statistics are provided in Table 1 and Table 2.

\section{Empirical Results}

Before turning to the results of the econometric analysis, we discuss some key patterns of technological specialization in regions. Figure 2 shows the probability of entry of a new technology in a given region (y-axis) for different quantiles ${ }^{6}$ of relatedness density (x-axis). We observe three clear patterns. First, and in line with the existing literature, the probability of entry increases with the level of relatedness density. In fact, the mean probability of entry for the highest level of relatedness (85-95\% quantile) is almost three times higher than for the lowest one (5-15\% quantile). The relation between the probability that a location will develop expertise in a new technology and the number of related activities that are already present in that location is known in the literature as the principle of relatedness (Hidalgo et al., 2017). Second, technologies in which a region participates in subsidized $R \& D$ projects are indeed associated with a higher probability to enter a region's portfolio. This is true for observations across all different levels of relatedness density. However, it seems that the relation between funding and entry is not uniform accross the different levels of relatedness. We observe that there is a very small difference in the likelihood of entry of funded and not funded technologies for very low and very high level of relatedness. Funding seems to make a big difference for mid-level of relatedness, above $15 \%$ and below $55 \%$. There is almost no differences for the highest level of relatedness (85-95\% quantile). This might imply that there is a need for a critical mass of knowledge and capabilities for innovation policy to be effective, but also that innovation policy might not be needed at all if the level of relatedness is already high.

\footnotetext{
${ }^{6}$ Quantiles are used as the number of observations for high levels of relatedness denisty is too low to be interpreted in a reliable manner.
} 
Figure 2: Differences of Mean Entry Probabilities

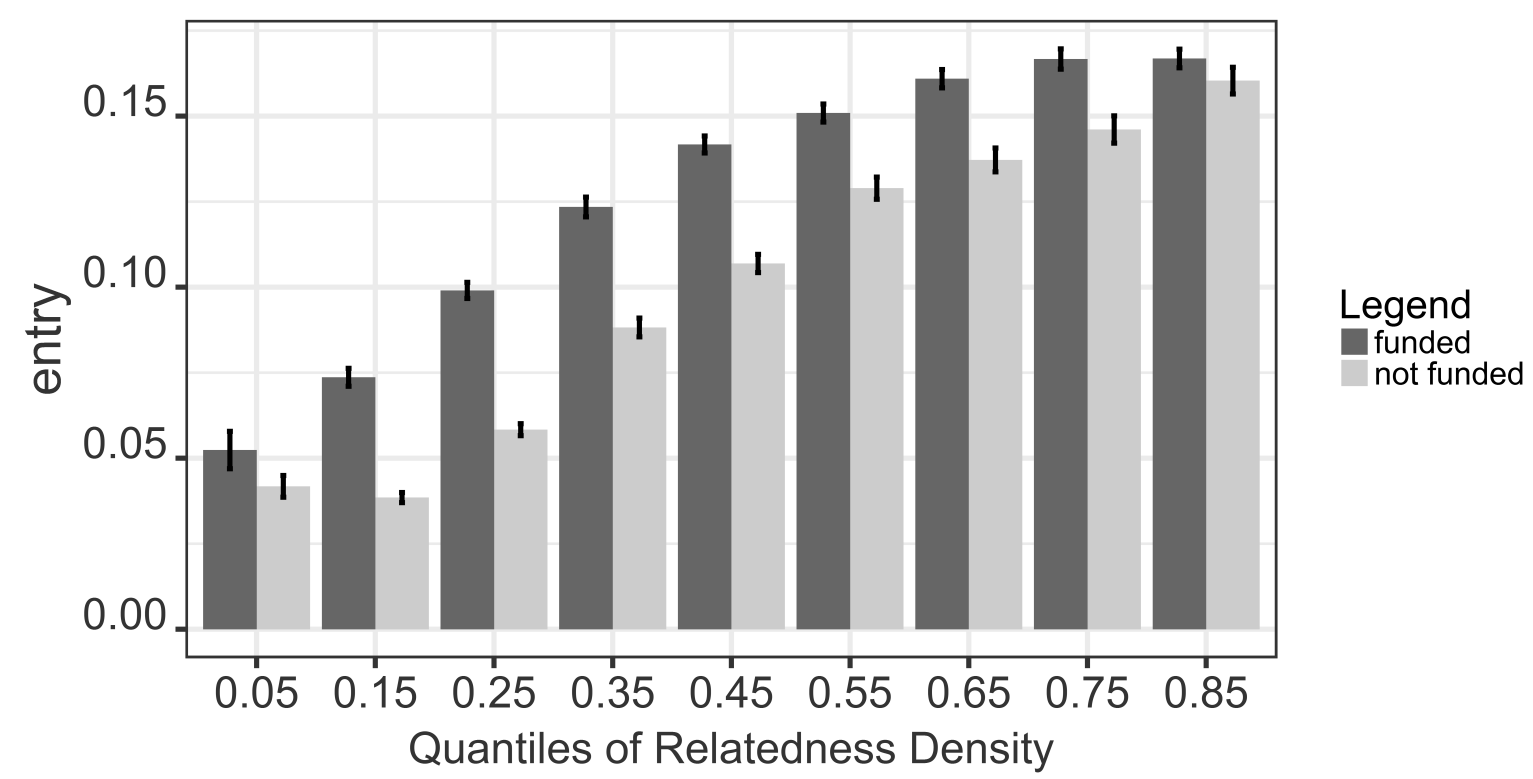

Note: This figure depicts differences in the mean entry probability between funded and non-funded technologies for different levels of relatedness density. These levels are delineated based on quantiles whereas the lower threshold value is shown as the $\mathrm{x}$-axis label. Thus, the first two bars refer to the quantiles between above $5 \%$ to $15 \%$ and the last bars to the quantiles above $85 \%$ up to $95 \%$. The mean entry values are depicted on the $y$-axis. The whisker on each bar represents the standard errors.

We will now turn to the results of our econometric analysis. Table 3 presents the results for our model as presented in the previous section. We estimate different model versions, adding variables step-by-step to check robustness and highlight changes when another variable is added.

As Model 1 reveals, funding indeed seems to have a positive and significant impact on the entry of a new technology, which confirms hypothesis 1 . When looking at the marginal effect however, it becomes obvious that the impact is small. Thus, when not controlling for anything else, a 10\% increase of project participations will be associated with a $2 \%$ relative increase of the mean probability of a technology to enter the region's portfolio ${ }^{7}$. The effect of relatedness density is as expected, significantly positive (model 2). Also the scope of its effect is within the range of previous findings (e.g. Boschma et al., 2015). According to model 2, a $10 \%$ increase in relatedness density would lead to a $31 \%$ relative increase in the entry probability ${ }^{8}$. Model 3 presents the effect the variables have together and adds the interaction effect. In this specification, the variables of interest keep their effects, while the interaction effect turns out to be negative and significant. Thus, in line with hypothesis 2 , this would suggest that higher R\&D subsidization can to some extent compensate for a lack of relatedness.

In Model 4, a row of control variables on the region and technology level are presented. All of these turn out to be significant. Regarding the region level variables, the model indicates positive effects of the GDP per capita of a region and surprisingly, negative

\footnotetext{
${ }^{7}$ Since the FP variable has been log-transformed, we find the relative increase by first multiplying $\log (\mathrm{FP})$ coefficient by $\log (1+10 \%)$ and by then dividing this result by the constant (mean probability of entry since all variables have been mean-centered), i.e. $0.0242^{*} \log (1.1) / 0.1067=0.02$.

${ }^{8} 0.0033 * 10 / 0.1067=0.31$
} 
Table 3: Regression Results

\begin{tabular}{|c|c|c|c|c|c|c|}
\hline & \multicolumn{6}{|c|}{ Dependent variable: entry } \\
\hline & $\begin{array}{l}\text { Pooled FP } \\
\text { (1) }\end{array}$ & $\begin{array}{l}\text { Pooled RD } \\
\text { (2) }\end{array}$ & $\begin{array}{c}\text { Baseline } \\
\text { (3) }\end{array}$ & $\begin{array}{l}\text { Pooled Controls } \\
\text { (4) }\end{array}$ & $\begin{array}{l}\text { Full Model } \\
\qquad(5)\end{array}$ & $\begin{array}{l}\text { Full Model F.E. } \\
\qquad(6)\end{array}$ \\
\hline $\log (F P)$ & $\begin{array}{c}0.0242^{* * *} \\
(0.0007)\end{array}$ & & $\begin{array}{c}0.0174^{* * *} \\
(0.0008)\end{array}$ & & $\begin{array}{c}0.0083^{* * *} \\
(0.0010)\end{array}$ & $\begin{array}{c}0.0171^{* * *} \\
(0.0020)\end{array}$ \\
\hline RD & & $\begin{array}{l}0.0033^{* * *} \\
(0.00004)\end{array}$ & $\begin{array}{l}0.0031^{* * *} \\
(0.00005)\end{array}$ & & $\begin{array}{c}0.0022^{* * *} \\
(0.0001)\end{array}$ & $\begin{array}{c}0.0003^{* * *} \\
(0.0001)\end{array}$ \\
\hline FP Dens & & & & $\begin{array}{l}0.0017^{* * *} \\
(0.00004)\end{array}$ & $\begin{array}{c}0.0011^{* * *} \\
(0.0001)\end{array}$ & $\begin{array}{c}0.0006^{* * *} \\
(0.0001)\end{array}$ \\
\hline GDP/CAP & & & & $\begin{array}{c}0.0020^{* * *} \\
(0.0001)\end{array}$ & $\begin{array}{c}0.0008^{* * *} \\
(0.0001)\end{array}$ & $\begin{array}{c}-0.0029^{* * *} \\
(0.0010)\end{array}$ \\
\hline Pop. Dens & & & & $\begin{array}{c}-0.00001^{* * *} \\
(0.000001)\end{array}$ & $\begin{array}{c}-0.000005^{* * *} \\
(0.000001)\end{array}$ & $\begin{array}{l}0.00004 \\
(0.0001)\end{array}$ \\
\hline GERD (1000) & & & & $\begin{array}{c}-0.0088^{* * *} \\
(0.0007)\end{array}$ & $\begin{array}{c}-0.0071^{* * *} \\
(0.0007)\end{array}$ & $\begin{array}{l}-0.0072 \\
(0.0090)\end{array}$ \\
\hline Tech. Growth & & & & $\begin{array}{l}0.0001^{* * *} \\
(0.00001)\end{array}$ & $\begin{array}{l}0.0001^{* * *} \\
(0.00002)\end{array}$ & $\begin{array}{l}0.0001^{* * *} \\
(0.00002)\end{array}$ \\
\hline $\log (F P) \times R D$ & & & $\begin{array}{c}-0.0010^{* * *} \\
(0.0001)\end{array}$ & & $\begin{array}{c}-0.0007^{* * *} \\
(0.0001)\end{array}$ & $\begin{array}{c}-0.0005^{* * *} \\
(0.0001)\end{array}$ \\
\hline Time F.E. & No & No & No & No & No & Yes \\
\hline Tech. F.E & No & No & No & No & No & Yes \\
\hline Region F.E & No & No & No & No & No & Yes \\
\hline Constant & $\begin{array}{c}0.1067^{* * *} \\
(0.0006)\end{array}$ & $\begin{array}{c}0.1067^{* * *} \\
(0.0006)\end{array}$ & $\begin{array}{c}0.1097^{* * *} \\
(0.0006)\end{array}$ & $\begin{array}{c}0.1075^{* * *} \\
(0.0007)\end{array}$ & $\begin{array}{c}0.1101^{* * *} \\
(0.0007)\end{array}$ & \\
\hline Observations & 284,508 & 284,508 & 284,508 & 212,751 & 212,751 & 212,751 \\
\hline $\mathrm{R}^{2}$ & 0.0047 & 0.0197 & 0.0220 & 0.0208 & 0.0260 & 0.0669 \\
\hline Adjusted $\mathrm{R}^{2}$ & 0.0047 & 0.0197 & 0.0220 & 0.0208 & 0.0260 & 0.0632 \\
\hline Residual Std. Error & r 0.3080 & 0.3057 & 0.3053 & 0.3044 & 0.3036 & 0.2978 \\
\hline
\end{tabular}

effects for the population density and the overall expenditure for $\mathrm{R} \& \mathrm{D}$ of a region. The latter, can be partially explained by R\&D investment strategies of firms that mainly aim at strengthening existing specialisations (Frenken, 2017). The model suggests further that technology growth as well as the a region's project participations in related technologies are positively associated with the entry probability of a technology. In model 5 , this set of control variables is added to the model of interest. In so doing the results remain stable. In the final model (model 6) time, regional and technology fixed effects are added. The sign and significance of the variables of interest remain the same. Changes happen however among the control variables. Thus, GDP per capita turns negative, while population 
density and the overall expenditure for R\&D of a region lose their significance. Overall, the model confirms our hypotheses, that subsidisation can influence regional diversification. But in order to make more detailed statements about the scope of the interrelationship between relatedness and subsidisation as well as the causal effects of such subsidizations, further analyses are needed.

To shed more light on the interaction term we analyze whether the effect of subsidization is the same across all levels of relatedness density. In order to investigate this, we split the data set into three, based on the level relatedness density.

This leads to a group of low (5-15\% quantile), middle (45-55\% quantile) and high (85-95\% quantile) levels of $R D$. For these subsets, we estimate three additional models each. The first only shows the effects of participation, without controlling for anything else. In the second model, we add the set of control variables and in the third we include region, technology and time fixed effects. The corresponding results are presented in Table 4. These models confirm the pattern presented in Figure 2, i.e. that funding is most associated with entry for medium level of relatedness. In fact, funding has a positive and significant effect across all models at a medium level of relatedness. When funding increases by about $10 \%$, the absolute probability of entry increases by about $0.7-1.0 \%$ depending on the specification. For low level of relatedness, however, the effects are not significant. For high level of relatedness, the relative impact is not significant with no controls, significant but negative with controls, and positive and significant in the fixed effects specification. Overall, these results indicate that funding seems to make the biggest difference for mid-level of relatedness.

\section{Discussion and Conclusion}

The recent debate about science and innovation policy is getting increasingly aware of the importance of structural change and region specific technological structures, for an effective allocation of funding (e.g. Balland et al., 2017). The aim of this paper was therefore to assess the relationship between public R\&D subsidisation and the emergence of new specialisations in European regions. In so doing we were especially interested in whether such subsidisations are positively associated with the emergence of new specialisations and to what extent they can compensate for lacking related capabilities, allowing less related technologies to emerge in regions. We conceptualised the technological evolution of regions as a branching process in which regions tend to develop new specialisations that are closely related to their current activities. Against this backdrop, we analysed the technological dynamics of 282 European NUTS2 regions, in terms of their patent applications, and their participations in collaborative R\&D projects, subsidised by the EU Framework Programmes, over a twelve-year period.

Our results confirm that technological dynamics in regions are not only highly pathdependent but also suggest that they are associated with a region's participations in publicly funded collaborative R\&D projects. Thus, we find that the number of a region's participation in FP projects indeed increases its likelihood to develop new specialisations in the respective technologies. However, the marginal effect is small. In line with our second hypothesis, we find that a high number of participations can to some extent compensate for a lack of relatedness. Additionally, we showed that this effect differs across different levels of relatedness density. We find evidence that R\&D subsidies have the highest impact if the level of relatedness with the new technology is neither too low (policy can not build a cathedral in the desert) nor too high (if all the capabilities are already 
Table 4: Regression Models for Different Levels of Relatedness Density

\begin{tabular}{|c|c|c|c|c|c|c|c|c|c|}
\hline & \multicolumn{9}{|c|}{ Dependent variable: entry } \\
\hline & $\begin{array}{c}\text { Low RD } \\
\text { (1) }\end{array}$ & $\begin{array}{c}\text { Low RD } \\
(2)\end{array}$ & $\begin{array}{c}\text { Low RD } \\
\text { (3) }\end{array}$ & $\begin{array}{l}\text { Mid RD } \\
(4)\end{array}$ & $\begin{array}{l}\text { Mid RD } \\
\text { (5) }\end{array}$ & $\begin{array}{l}\text { Mid RD } \\
\text { (6) }\end{array}$ & $\begin{array}{c}\text { High RD } \\
(7)\end{array}$ & $\begin{array}{c}\text { High RD } \\
(8)\end{array}$ & $\begin{array}{c}\text { High RD } \\
(9)\end{array}$ \\
\hline $\log (\mathrm{FP})$ & $\begin{array}{c}0.0115 \\
(0.0087)\end{array}$ & $\begin{array}{l}-0.0035 \\
(0.0118)\end{array}$ & $\begin{array}{l}-0.0006 \\
(0.0142)\end{array}$ & $\begin{array}{c}0.0133^{* * *} \\
(0.0021)\end{array}$ & $\begin{array}{c}0.0089^{* * *} \\
(0.0028)\end{array}$ & $\begin{array}{c}0.0164^{* * *} \\
(0.0047)\end{array}$ & $\begin{array}{l}-0.0004 \\
(0.0022)\end{array}$ & $\begin{array}{c}-0.0048^{*} \\
(0.0028)\end{array}$ & $\begin{array}{c}0.0291^{* * *} \\
(0.0055)\end{array}$ \\
\hline FP Dens & & $\begin{array}{c}0.0008 \\
(0.0006)\end{array}$ & $\begin{array}{c}0.0009 \\
(0.0011)\end{array}$ & & $\begin{array}{c}0.0007^{* * *} \\
(0.0002)\end{array}$ & $\begin{array}{c}0.0016^{* * *} \\
(0.0005)\end{array}$ & & $\begin{array}{c}0.0009^{* * *} \\
(0.0002)\end{array}$ & $\begin{array}{c}0.0003 \\
(0.0006)\end{array}$ \\
\hline GDP/CAP & & $\begin{array}{c}-0.00002 \\
(0.0004)\end{array}$ & $\begin{array}{l}-0.0084 \\
(0.0072)\end{array}$ & & $\begin{array}{c}0.0009^{* * * *} \\
(0.0002)\end{array}$ & $\begin{array}{c}0.0040 \\
(0.0029)\end{array}$ & & $\begin{array}{l}-0.0005 \\
(0.0005)\end{array}$ & $\begin{array}{l}-0.0048 \\
(0.0052)\end{array}$ \\
\hline Pop. Dens & & $\begin{array}{c}0.00001 \\
(0.00003)\end{array}$ & $\begin{array}{c}0.0005 \\
(0.0011)\end{array}$ & & $\begin{array}{c}0.000000 \\
(0.000004)\end{array}$ & $\begin{array}{l}-0.0002 \\
(0.0003)\end{array}$ & & $\begin{array}{l}-0.00001^{*} \\
(0.000005)\end{array}$ & $\begin{array}{l}-0.0006 \\
(0.0004)\end{array}$ \\
\hline GERD (1000) & & $\begin{array}{l}0.2855^{* *} \\
(0.1402)\end{array}$ & $\begin{array}{c}0.4294 \\
(0.3152)\end{array}$ & & $\begin{array}{l}-0.0023 \\
(0.0022)\end{array}$ & $\begin{array}{l}-0.0312 \\
(0.0323)\end{array}$ & & $\begin{array}{c}-0.0037^{*} \\
(0.0019)\end{array}$ & $\begin{array}{l}0.0543^{* *} \\
(0.0246)\end{array}$ \\
\hline Tech. Growth & & $\begin{array}{l}0.0003^{* *} \\
(0.0001)\end{array}$ & $\begin{array}{c}0.0002 \\
(0.0002)\end{array}$ & & $\begin{array}{c}0.0003^{* * *} \\
(0.0001)\end{array}$ & $\begin{array}{c}0.0002 \\
(0.0001)\end{array}$ & & $\begin{array}{c}0.0002^{* * *} \\
(0.0001)\end{array}$ & $\begin{array}{c}0.0001 \\
(0.0001)\end{array}$ \\
\hline Time F.E. & No & No & Yes & No & No & Yes & No & No & Yes \\
\hline Tech. F.E. & No & No & Yes & No & No & Yes & No & No & Yes \\
\hline Region F.E. & No & No & Yes & No & No & Yes & No & No & Yes \\
\hline Constant & $\begin{array}{c}0.0449^{* * *} \\
(0.0028)\end{array}$ & $\begin{array}{c}0.0466^{* * *} \\
(0.0032)\end{array}$ & & $\begin{array}{c}0.1276^{* * *} \\
(0.0018)\end{array}$ & $\begin{array}{c}0.1283^{* * *} \\
(0.0022)\end{array}$ & & $\begin{array}{c}0.1648^{* * *} \\
(0.0022)\end{array}$ & $\begin{array}{c}0.1628^{* * *} \\
(0.0026)\end{array}$ & \\
\hline Observations & 5,636 & 4,400 & 4,400 & 33,155 & 23,400 & 23,400 & 27,566 & 20,023 & 20,023 \\
\hline & 0.0003 & 0.0057 & 0.0995 & 0.0013 & 0.0048 & 0.0952 & 0.000001 & 0.0018 & 0.0911 \\
\hline Adjusted $\mathrm{R}^{2}$ & 0.0001 & 0.0044 & 0.0288 & 0.0012 & 0.0046 & 0.0618 & -0.00004 & 0.0015 & 0.0530 \\
\hline
\end{tabular}

Note: All independent variables are centred around their mean. All standard errors are clustered on the regional and technology level, and heteroscedasticity robust. Coefficients are significant at the ${ }^{*} \mathrm{p}<0.1 ;{ }^{* *} \mathrm{p}<0.05 ;{ }^{* * *} \mathrm{p}<0.01$ level. The models correspond to subsets of low ( $5 \%-15 \%$ quantile), middle (45\%-55\% quantile) and high ( $85 \%-95 \%$ quantile) levels of $R D$. 
present there is no need for policy).

These findings contribute very well to the on-going scientific debate about funding tools and delivers an evidence base for current theoretical considerations (see e.g. Frenken, 2017). Besides this epistemic contribution, our study is also novel in a methodological way, by establishing a convergence of funding data, on project level. This was done, using a text based classification approach, in which projects were assigned to certain technologies, based on their descriptions. This can be considered as a major advancement, as it allows to for a more detailed and targeted analysis of subsidisation data.

From these results, interesting implications for policy makers can be derived. As the literature on related variety and diversification processes already pointed out, regions are constrained in their possibilities for new activities by their incumbent knowledge and capabilities. Therefore and in order to use available funds efficiently, it is important to have an evidence base. As this study suggests, policy has, to a certain extent, the opportunity to facilitate less related new specialisations.

Further research should therefore aim at understanding the exact mechanisms more in detail. It will therefore be important to differentiate between the different channels through which STI policies can foster technological change in regions. A promising approach that can be taken in this regard is to investigate with more nuance the extent to which lacking capabilities can be complemented by collaborations. A second promising approach to test the claims made in this paper is to repeat a similar study on the micro level. Thus, as the new version of the EUPRO database links publications to projects, it can be investigated whether participating organisations and individuals change their scientific base and publishing behaviour due to project participations. Another important research avenue is to address the role of public policy in technological upgrading through the development of new specializations into more complex technologies (Balland \& Rigby, 2017; Hidalgo \& Hausmann, 2009; Albeaik et al., 2017).

However, the presented results should not be interpreted without considering their limitations. First and foremost, the technique applied to match FP projects and patent data introduces a set of problems. Due to the imperfection of the text classification, the subsidization of some technology fields may be underestimated, while on the other hand noise can be introduced when wrong technology fields are predicted. Additionally, as the matching was established using technological fields, the dependent and independent variable were on different levels. This causes a range of empirical problems and may lead to misestimations of the coefficients. Further, only a basic model was estimated, which is trying to capture a complex relationship. A key problem here can be seen in an allocation bias of the funds. This means that funds are a priori allocated in regions that already have an advanced $R \& D$ sector and are well embedded in $R \& D$ networks, which can imply that they are already more capable of diversifying into less related technologies. It is therefore not possible to make claims about causality, without conducting further analyses. Another limitation is that the funding granted under the FPs only represent a small portion of R\&D subsidies. We miss national and regional funding, that sometimes correlates with the FPs in their thematic orientation, but sometimes is (explicitly) complementary. An additional shortcoming arises from neglecting the spatial dimension and potential spatial autocorrelation; inter-regional knowledge spillovers that may influence the emergence of new specialisations are not accounted for. Lastly, no claims can be made about whether new technological specialisations are sustained and whether funding can also contribute to the scaling of new specialisations. Thus, technological dynamics of regions can be influenced not only by developments in their neighbouring regions (Boschma et al., 2016; 
Gao et al., 2017), but also by those of their collaborating partners (Hazır et al., 2016). It would therefore be adequate to also take into account spatial effects.

\section{Acknowledgements}

We would like to thank David Rigby for his involvement in this project, and for welcoming Wolf-Hendrik Uhlbach for a fruitful research visit. Funding from the Knowledge and Development Programme at the Austrian Institute of Technology is gratefully acknowledged, as well as financial support from the Regional Studies Association (RSA) through the Early Career Grant awarded to Pierre-Alexandre Balland. We also thank Ron Boschma, Koen Frenken, and Michael Storper for their helpful comments, colleagues from Utrecht University, the AIT Austrian Institute of Technology, the University of California, Los Angeles, and participants of the Eu-SPRI 2017 conference in Vienna. This work has been supported with the provision of original data via the RISIS (Research Infrastructure for and Innovation Policy Studies) infrastructure (risis.eu), using information from the EUPRO database on European Framework Programme participations. 


\section{References}

Acemoglu, D., Aghion, P., Bursztyn, L., \& Hemous, D. (2012). The environment and directed technical change. The American Economic Review, 102(1), 131-166.

Acs, Z. J., Anselin, L., \& Varga, A. (2002). Patents and innovation counts as measures of regional production of new knowledge. Research Policy, 31(7), 1069 1085. Retrieved from http://www.sciencedirect.com/science/article/pii/ S0048733301001846 doi: http://dx.doi.org/10.1016/S0048-7333(01)00184-6

Aghion, P., Boulanger, J., \& Cohen, E. (2011). Rethinking industrial policy. bruegel policy brief 2011/04, june 2011.

Aghion, P., David, P. A., \& Foray, D. (2009). Science, technology and innovation for economic growth: linking policy research and practice in STIG Systems. Research Policy, 38(4), 681-693.

Aghion, P., Dewatripont, M., Du, L., Harrison, A., \& Legros, P. (2012). Industrial policy and competition.

Albeaik, S., Kaltenberg, M., Alsaleh, M., \& Hidalgo, C. A. (2017). Measuring the knowledge intensity of economies with an improved measure of economic complexity. arXiv preprint arXiv:170\%.05826.

Arnold, E. (2012). Understanding long-term impacts of R\&D funding: The EU framework programme. Research Evaluation, 21(5), 332-343.

Arrow, K. (1962). Economic welfare and the allocation of resources for invention. In The rate and direction of inventive activity: Economic and social factors (pp. 609-626). Princeton University Press.

Arthur, W. B. (1994). Increasing returns and path dependence in the economy. University of michigan Press.

Azar, C., \& Sandén, B. A. (2011). The elusive quest for technology-neutral policies. Environmental Innovation and Societal Transitions, 1(1), 135 139. Retrieved from http://www.sciencedirect.com/science/article/pii/ S2210422411000098 doi: http://dx.doi.org/10.1016/j.eist.2011.03.003

Balland, P.-A. (2016). Relatedness and the geography of innovation. In R. Shearmur, C. Carrincazeaux, \& D. Doloreux (Eds.), Handbook on the geographies of innovation (p. 127-141). Northampton, MA: Edward Elgar Publishing.

Balland, P.-A. (2017). Econgeo: Computing key indicators of the spatial distribution of economic activities. , $R$ package version 1.3. Retrieved from https://github.com/ $\mathrm{PABalland/EconGeo}$

Balland, P.-A., Boschma, R., Crespo, J., \& Rigby, D. (2017). Smart specialization policy in the eu: Relatedness, knowledge complexity and regional diversification (Papers in Evolutionary Economic Geography No. 17.17). Utrecht University.

Balland, P.-A., \& Rigby, D. (2017). The geography of complex knowledge. Economic Geography, 1(93), 1-23.

Barca, F. (2009). Agenda for a reformed cohesion policy; a place-based approach to meeting european union challenges and expectations. European Communities.

Bathelt, H., Malmberg, A., \& Maskell, P. (2004). Clusters and knowledge: local buzz, global pipelines and the process of knowledge creation. Progress in Human Geography, 28(1), 31-56.

Blumenthal, M. S. (1998). Federal government initiatives and the foundations of the information technology revolution: lessons from history. The American Economic Review, 88(2), 34-39. 
Boschma, R. (2015). Towards an evolutionary perspective on regional resilience. Regional Studies, 49(5), 733-751.

Boschma, R. (2017). Relatedness as driver of regional diversification: a research agenda. Regional Studies, 51(3), 351-364. Retrieved from http://dx.doi.org/10.1080/ 00343404.2016.1254767 doi: 10.1080/00343404.2016.1254767

Boschma, R., Balland, P.-A., \& Kogler, D. F. (2015). Relatedness and technological change in cities: the rise and fall of technological knowledge in US metropolitan areas from 1981 to 2010. Industrial and Corporate Change, 24(1), 223-250.

Boschma, R., \& Capone, G. (2015). Institutions and diversification: Related versus unrelated diversification in a varieties of capitalism framework. Research Policy, $44(10), 1902-1914$.

Boschma, R., Frenken, K., Bathelt, H., Feldman, M., Kogler, D., et al. (2012). Technological relatedness and regional branching. Beyond territory: Dynamic geographies of knowledge creation, diffusion and innovation, 64-81.

Boschma, R., \& Gianelle, C. (2014). Regional branching and smart specialization policy. JRC technical reports $(06 / 2014)$.

Boschma, R., Martn, V., \& Minondo, A. (2016). Neighbour regions as the source of new industries. Papers in Regional Science, n/a-n/a. Retrieved from http://dx.doi .org/10.1111/pirs.12215 (PIRS-FA-2015-1448.R1) doi: 10.1111/pirs.12215

Boschma, R., Minondo, A., \& Navarro, M. (2013). The Emergence of New Industries at the Regional Level in Spain: A Proximity Approach Based on Product Relatedness. Economic Geography, 89(1), 29-51.

Breschi, S., \& Lenzi, C. (2013). Local buzz versus global pipelines and the inventive productivity of us cities. In T. Scherngell (Ed.), The geography of networks and rEd collaborations (pp. 299-315). Cham: Springer International Publishing. Retrieved from http://dx.doi.org/10.1007/978-3-319-02699-2_16 doi: 10.1007/978-3 $-319-02699-2 \_16$

Broekel, T. (2015). Do cooperative research and development (R\&D) subsidies stimulate regional innovation efficiency? Evidence from Germany. Regional Studies, 49(7), 1087-1110.

Broekel, T., Brachert, M., Duschl, M., \& Brenner, T. (2015). Joint REDD subsidies, related variety, and regional innovation (Working Papers on Innovation and Space No. 01.15). Philipps-Universität Marburg.

Chatterjee, S., \& Wernerfelt, B. (1991). The link between resources and type of diversification: Theory and evidence. Strategic management journal, 12(1), 33-48.

Cohen, W. M., \& Levinthal, D. A. (1990). Absorptive capacity: A new perspective on learning and innovation. Administrative science quarterly, 128-152.

Colombelli, A., Krafft, J., \& Quatraro, F. (2014). The emergence of new technologybased sectors in european regions: A proximity-based analysis of nanotechnology. Research Policy, 43(10), 1681-1696.

Cortinovis, N., Xiao, J., Boschma, R., \& van Oort, F. (2016). Quality of government and social capital as drivers of regional diversification in Europe (Papers in Evolutionary Economic Geography No. 16.10). Utrecht University, Section of Economic Geography.

Crespo, J., Suire, R., \& Vicente, J. (2013). Lock-in or lock-out? how structural properties of knowledge networks affect regional resilience. Journal of Economic Geography, $14(1), 199-219$.

Czarnitzki, D., \& Fier, A. (2003). Publicly funded R\&D collaborations and patent 
outcome in Germany.

Dekker, R., \& Kleinknecht, A. (2008). The EU Framework Programs: Are they worth doing? MPRA Paper, 8503.

Eck, N. J. v., \& Waltman, L. (2009). How to normalize cooccurrence data? an analysis of some well-known similarity measures. Journal of the American Society for Information Science and Technology, 60(8), 1635-1651. Retrieved from http://dx.doi.org/10.1002/asi.21075 doi: 10.1002/asi.21075

Essletzbichler, J. (2015). Relatedness, industrial branching and technological cohesion in US metropolitan areas. Regional Studies, 49(5), 752-766.

Fleming, L. (2001). Recombinant uncertainty in technological search. Management science, 47(1), 117-132.

Foray, D., David, P. A., \& Hall, B. (2009). Knowledge Economists Policy Brief n 9.

Frenken, K. (2017). A complexity-theoretic perspective on innovation policy. Complexity, Governance \& Networks(1), 35-47.

Frenken, K., Van Oort, F., \& Verburg, T. (2007). Related variety, unrelated variety and regional economic growth. Regional Studies, 41(5), 685-697.

Gao, J., Jun, B., Pentland, A., Zhou, T., \& Hidalgo, C. A. (2017). Collective learning in china's regional economic development. arXiv preprint arXiv:1703.01369.

Guellec, D., \& De La Potterie, B. V. P. (2000). The impact of public r\&d expenditure on business $r \& d$.

Hazır, C. S., LeSage, J., \& Autant-Bernard, C. (2016). The role of r\&d collaboration networks on regional knowledge creation: Evidence from information and communication technologies. Papers in Regional Science, n/a-n/a. Retrieved from http:// dx.doi.org/10.1111/pirs. 12267 (10.1111/pirs.12267) doi: 10.1111/pirs.12267

Heller-Schuh, B., Barber, M., Züger, M., \& Scherngell, T. (2015). Report on the content and technical structure of eupro v\%.4.11 (task 1 of wp6) (Tech. Rep.). AIT Austrian Institute of Technology.

Hidalgo, C., Balland, P., Boschma, R., Delgado, M., Feldman, M., Frenken, K., .. Zhu, S. (2017). The principle of relatedness. working paper.

Hidalgo, C., \& Hausmann, R. (2009). The building blocks of economic complexity. proceedings of the national academy of sciences, 106 (26), 10570-10575.

Hidalgo, C., Klinger, B., Barabási, A.-L., \& Hausmann, R. (2007). The product space conditions the development of nations. Science, 317(5837), 482-487.

Jacob, J., Sanditov, B., Smirnov, E., Wintjes, R., Surpatean, A., Notten, A., \& Sasso, S. $(2015,2)$. Inventory of the patents and publications of FPry projects in the field of ICT. European Commission.

Jurka, T. P. (2012). Maxent: An r package for low-memory multinomial logistic regression with support for semi-automated text classification. The $R$ Journal, 4 (1), 56-59.

Kogler, D. F., Essletzbichler, J., \& Rigby, D. L. (2017). The evolution of specialization in the eu15 knowledge space. Journal of Economic Geography, 17(2), 345. Retrieved from thttp://dx.doi.org/10.1093/jeg/lbw024 doi: 10.1093/jeg/lbw024

Lazonick, W., \& ner Tulum. (2011). \{US\} biopharmaceutical finance and the sustainability of the biotech business model. Research Policy, 40(9), 1170 1187. Retrieved from http://www.sciencedirect.com/science/article/pii/ S0048733311001028 doi: https://doi.org/10.1016/j.respol.2011.05.021

Lee, K., \& Lim, C. (2001). Technological regimes, catching-up and leapfrogging: findings from the korean industries. Research policy, 30(3), 459-483. 
Mazzucato, M. (2016). From market fixing to market-creating: a new framework for innovation policy. Industry and Innovation, 23(2), 140-156.

McCann, P., \& Ortega-Argilés, R. (2011). Smart specialisation, regional growth and applications to EU cohesion policy. Documents de treball IEB(14), 1-32.

Motoyama, Y., Appelbaum, R., \& Parker, R. (2011). The national nanotechnology initiative: Federal support for science and technology, or hidden industrial policy? Technology in Society, 33(12), 109 - 118. Retrieved from http://www.sciencedirect .com/science/article/pii/S0160791X1100011X doi: https://doi.org/10.1016/ j.techsoc.2011.03.010

Neffke, F., Henning, M., \& Boschma, R. (2011). How do regions diversify over time? Industry relatedness and the development of new growth paths in regions. Economic Geography, 87(3), 237-265.

Nelson, R. R., \& Winter, S. G. (1982). An evolutionary theory of economic change. Harvard University Press.

Nemet, G. F. (2009). Demand-pull, technology-push, and government-led incentives for non-incremental technical change. Research Policy, 38(5), 700-709.

Pavitt, K. (1998). The inevitable limits of eu r\&d funding. Research policy, 27(6), $559-568$.

Peters, M., Schneider, M., Griesshaber, T., \& Hoffmann, V. H. (2012). The impact of technology-push and demand-pull policies on technical change does the locus of policies matter? Research Policy, 41(8), 1296 - 1308. Retrieved from http://www .sciencedirect.com/science/article/pii/S0048733312000376 doi: http:// dx.doi.org/10.1016/j.respol.2012.02.004

Petralia, S., Balland, P.-A., \& Morrison, A. (2017). Climbing the ladder of technological development. Research Policy, 46(5), 956 - 969. Retrieved from http://www .sciencedirect.com/science/article/pii/S004873331730063X doi: https:// doi.org/10.1016/j.respol.2017.03.012

Rietschel, E. T. (2010). Evaluation of the sixth framework programmes for research and technological development 2002-2006: Report of the expert group. EUR-OP.

Rigby, D. L. (2015). Technological relatedness and knowledge space: entry and exit of US cities from patent classes. Regional Studies, 49(11), 1922-1937.

Rodrik, D. (2004). Industrial Policy for the Twenty-First Century (Tech. Rep.). CEPR Discussion Papers.

Scherngell, T., \& Lata, R. (2013). Towards an integrated european research area? findings from eigenvector spatially filtered spatial interaction models using european framework programme data. Papers in Regional Science, 92(3), 555-577.

Schmoch, U. (2008). Concept of a technology classification for country comparisons. Final report to the world intellectual property organisation (wipo), WIPO.

Steijn, M. (2017). Improvement on the association strength: implementing probability measures based on combinations without repetition (Tech. Rep.). Utrecht University.

Vicente, J. (2016). Economie des clusters. Repères. La Découverte.

Wanzenböck, I., Scherngell, T., \& Brenner, T. (2014). Embeddedness of regions in european knowledge networks: a comparative analysis of inter-regional r\&d collaborations, co-patents and co-publications. The Annals of Regional Science, 53(2), $337-368$.

Weber, K. M., \& Rohracher, H. (2012). Legitimizing research, technology and innovation policies for transformative change: Combining insights from innovation systems and multi-level perspective in a comprehensive failures framework. Research Policy, 


\section{Appendix A - Number of participations and rate of entry}

Figure 3: Correlation between Participations and Rate of Entry

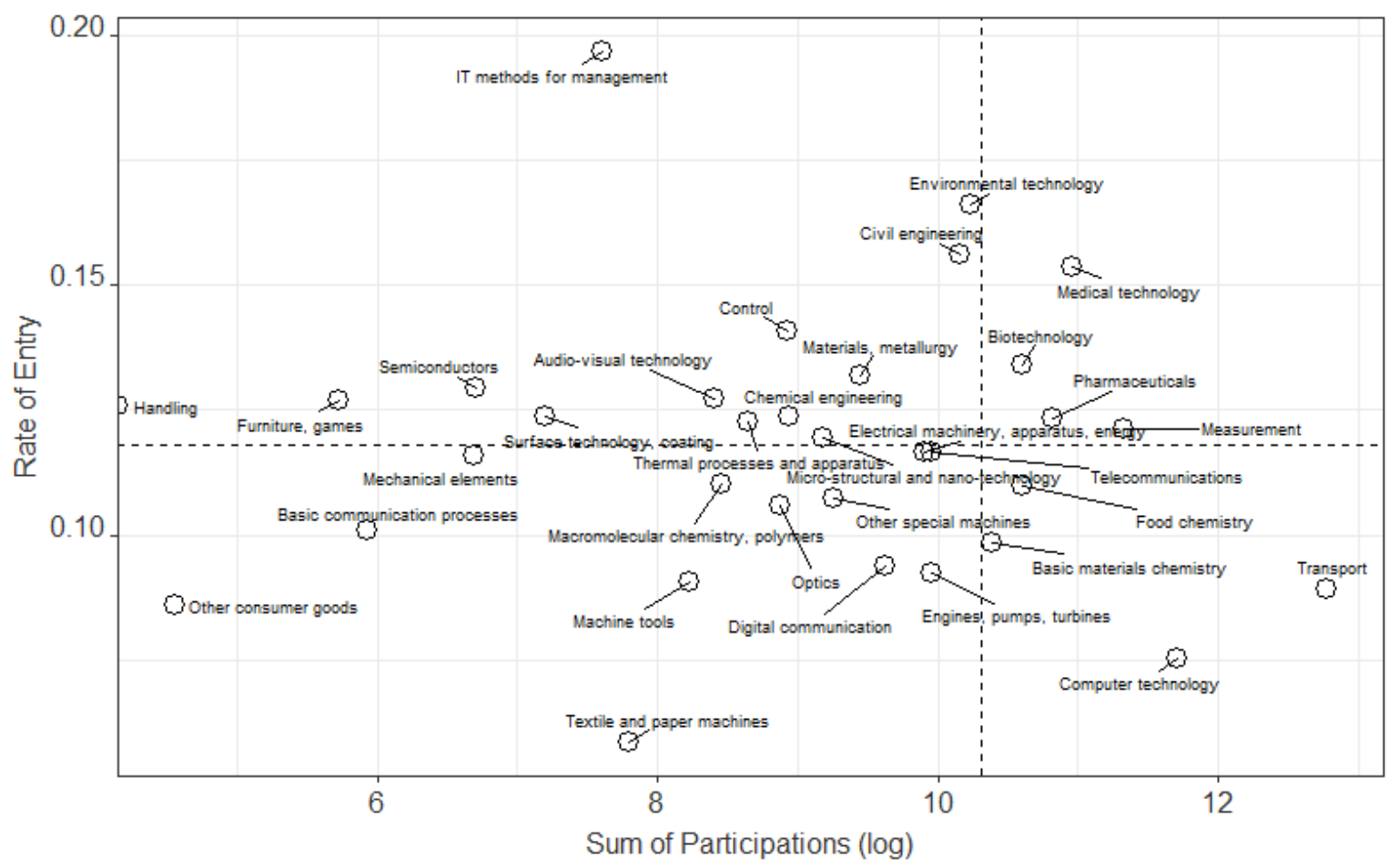

Note: Each dot represents one technology field. The sum of participations is the sum of regional participations in the respective field. The rate of entry is the average of the number of new technologies (IPC-classes), belonging to a technology field, divided by the number of possible entries. The dashed lines represent the mean values for each variable.

Further, and as Figure 3 reveals, the entry probability is also positively associated with number of participations. This figure depicts the logarithm of the overall number of project participations by technology fields on the x-axis and their associated rate of entry on the $y$-axis. The size of the dots indicates the absolute number of entries of IPC classes contained in the respective field. This figure also entails information about the prioritization of technology fields in the FPs. Thus, most participations were in the fields of Transport, Computer Technology Measurement Medical Technology Pharmaceuticals and Organic Fine Chemistry. Technology fields that contained least participations were Handling, Other consumer goods, Furniture and Games and Basic Communication Processes. The technology field IT Methods for Management, appears to be an outlier. This can have two possible explanations. On the one hand is this field closely related to the field Computer Technology, which can lead to misclassifications in the matching procedure. Secondly, it is a relatively small technology field, which means, that it is also highly sensitive to small numbers of entries. 